\title{
Climate and climate change
}

\author{
Ilan Kelman*, Tim Colbourn ${ }^{\dagger}$, Anthony Costello ${ }^{\dagger}$, \\ Lucien Georgeson", Sari Kovats $\$$, Mark Maslin`, \\ Andrew Newsham ${ }^{* *}$, Peter Sammonds ${ }^{\dagger \dagger}$, \\ Frauke Urban $^{* *}$, Jeff Waage ${ }^{\ddagger \ddagger}$ and Paul Wilkinson ${ }^{\S \S}$
}

${ }^{*}$ University College London, Institute for Global Health and Institute for Risk and Disaster Reduction, 'University College London, Institute for Global Health, "University College London, Department of Geography, ${ }^{\varsigma}$ London School of Hygiene and Tropical Medicine, Department of Social and Environmental Research, 'University College London, Department of Geography, ${ }^{*}$ School of Oriental and African Studies, Centre for Environment, Development and Policy, ${ }^{\dagger}$ University College London, Department of Earth Sciences, ${ }^{\ddagger}$ London International Development Centre; School of Oriental and African Studies, Centre for Development, Environment and Policy, ${ }^{5 s}$ London School of Hygiene and Tropical Medicine, Department of Social and Environmental Health Research

\section{Introduction}

In this chapter, we aim to summarise the developments in international goal setting for, and measurement of climate change. Two definitions are needed from the glossary of the Intergovernmental Panel on Climate Change (IPCC 2014):

Adaptation: The process of adjustment to actual or expected climate and its effects. In human systems, adaptation seeks to moderate harm or

\section{How to cite this book chapter:}

Kelman, I, Colbourn, T, Costello, A, Georgeson, L, Kovats, S, Maslin, M, Newsham, A, Sammonds, P, Urban, F, Waage, J, and Wilkinson P. 2015. Climate and climate change. In: Waage, J and Yap, C. (eds.) Thinking Beyond Sectors for Sustainable Development. Pp. 11-17. London: Ubiquity Press. DOI: http://dx.doi. org/10.5334/bao.b 
exploit beneficial opportunities. In natural systems, human intervention may facilitate adjustment to expected climate and its effects.

Mitigation: A human intervention to reduce the sources or enhance the sinks of greenhouse gases.

Note that this definition of adaptation distinguishes between human and natural systems, which is not common practice in sustainability debates. The definition of mitigation is also different from that used in most other fields.

\section{What is the historical process by which goal setting in this sector has developed?}

Three examples of past processes are provided here: the international policy process, the international scientific process, and examples of non-international processes (for a more detailed discussion please see Maslin 2014).

The main international policy process on climate change is the UNFCCC Conference of the Parties (COP). It started by seeking an international legally binding treaty on goals for climate change mitigation, which led to the Kyoto Protocol, the only international legally binding treaty on the topic. The Kyoto Protocol includes the important principle of 'common but differentiated responsibilities', referring to 'Annex 1 countries' - namely the richer, more developed countries with historically the most emissions - as having more responsibility for climate change mitigation than other countries. The specific goal of the Kyoto Protocol was that the Annex 1 countries committed to reducing their overall emissions of such gases by at least five per cent below 1990 levels in the commitment period 2008 to 2012. Today, the UNFCCC COP process also covers aspects of climate change adaptation. The general consensus is that country governments have no real incentive to reduce their greenhouse gas emissions or even to help others to substantively adapt, so there will need to be major progress soon if a worthwhile agreement is to be achieved.

The main international scientific process is the Intergovernmental Panel on Climate Change (IPCC) that provides a statement on the synthesis and assessment of the current state of climate change science. Each IPCC report undergoes a government review process and the Summary for Policymakers is debated and agreed by the member governments, currently numbering 195; thus, the report represents a political consensus of the current state of scientific knowledge. In the IPCC report from 2013-2014, the Fifth Assessment Report (AR5), new future greenhouse gas emissions scenarios called Representative Concentration Pathways (RCPs) are used. Relative to earlier scenarios, they consider a much wider variable input to the social-economic models including population, land use, energy intensity, energy use, and regionally differentiated development. These RCPs have been constructed to illustrate the consequences of different regional and global political policies up until 2100. 
Other processes have developed their own goals outside of the UNFCCC and IPCC processes, such as:

- In 2008, the United Nations Environment Programme (UNEP) started a Climate Neutral Network with countries such as Costa Rica, cities such as Arendal in Norway, and corporations such as Senoko Energy Pte Ltd (a Singaporean power company), aiming for clear carbon-related targets. The Network closed in 2011.

- The World Business Council for Sustainable Development adopted the goal of limiting global temperature rise to $2^{\circ} \mathrm{C}$ above pre-industrial levels under their Action 2020 plan, launched in 2013. Many member companies are now collaborating and developing sustainable investment mechanisms.

- The UK government passed the 2008 Climate Change Act, which established the world's first legally binding climate change target. The UK aims to reduce its greenhouse gas emissions by at least 80 per cent (from the 1990 baseline) by 2050 .

- Binding EU legislation (The 2020 climate and energy package), known as the 20-20-20 targets, set three key objectives for 2020:

- A 20 per cent reduction in EU greenhouse gas emissions from 1990 levels;

- Raising the share of EU energy consumption produced from renewable resources to 20 per cent;

- A 20 per cent improvement in the EU's energy efficiency.

- Mexico became the world's second country to pass legally binding targets, including a 30 per cent reduction in the growth of greenhouse gas emissions by 2020 and 50 per cent by 2050 .

- The Carbon Disclosure Project (CDP) monitors emissions from companies and 120 cities.

- Since 2008 the Harvard University Sustainability Plan, which is developed by a task force of students, academics, and staff, has set goals for emissions and energy as well as promoting the use of research to increase efficiency on campus.

- Pension funds and shareholder action has led to divestment campaigns against fossil fuel companies. As one example, the Universities Superannuation Scheme (USS) pension scheme in the U.K. has a campaign regarding ethical investment http://listentouss.org while a report by Cleveland and Reibstein (2015) describes opportunities for universities to divest from fossil fuels.

- The Sustainable Energy for All (SE4A) initiative has three objectives to be achieved by 2030 , one of which is achieving universal access to modern energy services. The International Energy Agency estimates that this will partly be achieved by small-scale, decentralised, renewable energy technology that will contribute to climate change mitigation.

At times, the wider green agenda (including biodiversity conservation, pollution prevention, and tackling environmental contamination) has been seen 
as synonymous with the climate change mitigation agenda. In reality, climate change mitigation efforts can cause or exacerbate environmental problems, with literature showing how carbon capture and storage/sequestration (CCS), carbon offsets, large-scale geoengineering, and the United Nations Collaborative Programme on Reducing Emissions from Deforestation and Forest Degradation (UN-REDD) programme are neither particularly environmentally friendly nor effective for tackling climate change (Beymer-Farris \& Bassett 2012; Dodds et al. 2012). Instead, climate change mitigation should be viewed as necessary, but not sufficient for an overall green agenda, and wider contexts should always be considered.

\section{What progress has been achieved in this sector through the Millennium Development Goals and other processes?}

Historically, the climate change agenda focused on mitigation. When adaptation was first discussed, many adamantly opposed a shift in focus because they felt that it was giving up the fight to stop climate change and adopting a fatalistic view; implying that we must deal with climate change because we cannot stop it. Now, both mitigation and adaptation are accepted as necessary. In fact, when the IPCC and UNFCCC COP processes were starting, many advocated for joining mitigation and adaptation. Instead, the two processes were explicitly separated, which continued despite literature showing their complementarity (Dang, Michaelowa \& Tuan 2003; Kane \& Shogren 2000). Finally, some movement is now being made at the IPCC and UNFCCC COP levels to show how mitigation and adaptation can, and should, support each other and are not separate activities.

Some programmes with various degrees of success (many are voluntary with no real enforcement mechanism and often without adequate monitoring mechanisms) are:

- The UNFCCC COP process led to the Kyoto Protocol, with its legally binding mitigation target, which was not fully reached.

- The IPCC continues to publish a periodic synthesis and assessment of the political consensus of the current state of scientific knowledge on climate change science, while delving into more specific topics through special reports on, for example, renewable energy sources and extreme events. The IPCC has also made progress on capacity for metrics and measurements, but there are nonetheless problems with establishing emissions baselines due to uptake of greenhouse gases by the oceans and the biosphere.

- The UK, EU, and Mexico climate change targets are currently legally binding, but they could nonetheless be rescinded later.

- The UN-REDD and related processes have encountered problems as sequestration due to reforestation and other activities is not well-documented or easily documentable. 
- Under the UNFCCC, the United Nations-designated Least Developed Countries (LDCs) are mandated to produce national adaptation programmes of action (NAPAs) to summarise and build on existing strategies and knowledge. Also under the UNFCCC, developing countries can report nationally appropriate mitigation actions (NAMAs).

- The Clean Development Mechanism (CDM) under the Kyoto Protocol permits developed countries to gain carbon credits for implementing emissionreduction projects in developing countries. The CDM is considered to have failed because it operates only at the international level, whereas multilevel governance and multiple mechanisms are needed and must be connected. Otherwise, abuse of CDM approaches, deliberate or inadvertent, can occur, as shown in Latin America (Lokey 2009).

- Regional Climate Innovation Centres have been set up in several developing countries, including Kenya and the Caribbean, with the aim of increasing research and development, testing, and diffusion of climate-relevant innovation, for both mitigation and adaptation.

\section{What is the current debate about future goal setting?}

There are three principal approaches to mitigation:

- The current political consensus is to limit the average global mean temperature rise to $2^{\circ} \mathrm{C}$. Although this is not enshrined in any international agreement, it is repeatedly referenced by the UNFCCC, the EU, and the Small Island Developing States (SIDS). The global mean temperature record has been instrumental in focusing attention on climate change, and is a simple and clear metric for politicians to use for assessing progress and failure. It does not capture the full range of climate change impacts or the problem of potentially irreversible changes. The carbon budget to keep temperature rises below $2^{\circ} \mathrm{C}$ is likely to be spent by 2040 .

- Another approach is to be under a specific average global level of parts per million (ppm) of $\mathrm{CO}_{2}$ (equivalent) in the atmosphere. Note that a specific temperature rise does not give a unique ppm solution (and vice versa), which creates a political problem, because an outcome is not clear for a given target. Examples of ppm levels suggested are $350 \mathrm{ppm}$ (Hansen et al. 2008) and 300 ppm (Target 300 Campaign 2015). At the global scale, the atmospheric concentration of $\mathrm{CO}_{2}$ has increased from a preindustrial value of approximately $280 \mathrm{ppm}$ to above $400 \mathrm{ppm}$ (Tans \& Keeling 2013).

- A third example of an approach is to seek alternatives to globally averaged quantitative targets. One example is two tonnes per person per year of carbon, as advocated by the Global Commons Institute since 1989, which could also suggest personal goals for $\mathrm{CO}_{2}$ or $\mathrm{CO}_{2}$ equivalents. If the 
individual limit is then slowly reduced, this yields a form of the Contraction and Convergence approach.

A significant impediment to future goal setting is that the UNFCCC COP and IPCC processes are consensual rather than democratic, leading to significant trouble in getting all parties on board all the time. That has meant that the trajectory of emission reduction is seen as proceeding far too slowly, with many emissions left out of control regimes, such as international shipping and aviation. The EU wanted to include aviation in the already existing EU Emissions Trading System, but an uproar followed and the plan was not fulfilled. Similarly, Australia passed a carbon tax in 2012, which was later rescinded following a change in government two years later.

For adaptation, the main targets relate to reducing any losses and damage from climate change impact, which has long been part of disaster risk reduction and development targets, such as the Hyogo Framework for Action and the MDGs/SDGs (Kelman \& Gaillard 2010). For mitigation and adaptation goals, many debates have long examined how to better integrate climate change with other development-related endeavours, as well as the long-standing efforts to stop the separation between mitigation and adaptation mentioned above. Furthermore, attribution of climate hazards to climate change is problematic, while 'adaptive capacity' can indicate the ability to deal with any development-related phenomena, whether linked to climate change or not.

\section{References}

Beymer-Farris, B. A., \& Bassett, T. J. (2012). The REDD menace: resurgent protectionism in Tanzania's mangrove forests. Global Environmental Change, 22(2), 332-341. DOI: http://dx.doi.org/10.1016/j.gloenvcha.2011.11.006

Cleveland, C. J., \& R. Reibstein (2015). The Path to Fossil Fuel Divestment for Universities: Climate Responsible Investment. Department of Earth and Environment, Boston University. Retrieved from http://energyincontext.com/wp-content/uploads/2015/02/University-DivestmentFossil-Fuels-Cleveland_Reibstein_02_13_15.pdf

Dang, H. H., Michaelowa, A., \& Tuan, D. D. (2003). Synergy of adaptation and mitigation strategies in the context of sustainable development: the case of Vietnam. Climate Policy, 3S1, S81-S96. DOI: http://dx.doi.org/10.1016/j. clipol.2003.10.006

Dodds, R., Kelman, I., Thiesen, N., McDougall, A., Garcia, J. \& Bessada, T. (2012). Industry Perspectives on Carbon Offsetting Programs in Canada and the USA. Sustainability: Science, Practice, \& Policy, 8(2), 31-41.

European Commission (EC). (Last updated 30 April 2015). The 2020 climate and energy package. Retrieved from http://ec.europa.eu/clima/policies/ package/index_en.htm 
Hansen, J., Sato, M., Kharecha, P., Beerling, D., Berner, R., Masson-Delmotte, V., Pagani, M., Raymo, M., Royer, D.L. \& Zachos, J.C. (2008). Target atmospheric CO2: Where should humanity aim? Open Atmospheric Science Journal, 2, 217-231, DOI: http://dx.doi.org/10.2174/1874282300802010217

Intergovernmental Panel on Climate Change (IPCC). (2014). IPCC Fifth Assessment Report: Working Group II. (AR5: 31st Session of the IPCC in Bali, 26-29 October 2009). IPCC, Geneva, Switzerland.

Kane, S., \& Shogren, J. F. (2000). Linking Adaptation and Mitigation in Climate Change Policy. Climatic Change, 45, 75-102. DOI: http://dx.doi. org/10.1023/A:1005688900676

Kelman, I., \& Gaillard, J. C. (2010). Embedding climate change adaptation within disaster risk reduction. In R. Shaw, J. M. Pulhin, \& J. J. Pereira (Eds.), Climate change adaptation and disaster risk reduction: issues and challenge. 23-46. Bingley: Emerald Group Publishing Limited. DOI: http://dx.doi. org/10.1108/S2040-7262(2010)0000004008

Lokey, E. (2009). Renewable energy project development under the clean development mechanism: a guide for Latin America. London: Earthscan Publishers.

Maslin, M. (2014). Climate change: a very short introduction, 3rd ed. Oxford: Oxford University Press.

Tans, P., \& Keeling, R. (2013). Trends in atmospheric carbon dioxide. NOAA/ ESRL, Boulder, Colorado and Scripps Institution of Oceanography, San Diego, California. Retrieved from http://www.esrl.noaa.gov/gmd/ccgg/trends Target 300 Campaign (2015). http://www.target300.org accessed on 8 May 2015. 
